\title{
Glycemic variability in normal glucose tolerance women with the previous gestational diabetes mellitus
}

\author{
Yong-mei Wang ${ }^{1 \dagger}$, Li-hua Zhao ${ }^{2 \dagger}$, Jian-bin Su², Hai-feng Qiao ${ }^{1}$, Xiao-hua Wang ${ }^{2}$, Feng Xu ${ }^{2}$, Tong Chen ${ }^{3}$, \\ Jin-feng Chen ${ }^{2}$, Gang Wu ${ }^{2}$ and Xue-qin Wang ${ }^{2^{*}}$
}

\begin{abstract}
Background: Women with previous gestational diabetes mellitus (pGDM) and postpartum normal glucose tolerance (NGT) may carry impaired islet $\beta$ cell secretion, insulin resistance and subsequent altered glucose homeostasis. And certain normoglycemic groups at risks of diabetes were presented with elevated glycemic variability. The aim of study was to investigate the glycemic variability in NGT women with pGDM.

Methods: Total 48 NGT women with pGDM (pGDM group) and 48 age- and BMI-matched NGT women without pGDM (control group) were recruited in the study. Integrated $\beta$ cell function was assessed with the Insulin SecretionSensitivity Index-2 (ISSI-2) derived from oral glucose tolerance test. All subjects were monitored using the continuous glucose monitoring system for consecutive $72 \mathrm{~h}$. The multiple parameters of glycemic variability included the mean blood glucose (MBG), standard deviation of blood glucose (SDBG), mean of daily differences (MODD), mean amplitude of glycemic excursions (MAGE) and the incremental areas above preprandial glucose values (AUC $C_{p p}$ ).

Results: The pGDM group had a higher MBG (6.5 $\pm 0.9 \mathrm{vs.} 5.9 \pm 0.8 \mathrm{mmol} / \mathrm{L}, p<0.05)$, SDBG (1.3 $\pm 0.3 \mathrm{vs}$. $0.9 \pm 0.2 \mathrm{mmol} / \mathrm{L}, p<0.05)$, MODD (1.4 \pm 0.3 vs. $1.1 \pm 0.2 \mathrm{mmol} / \mathrm{L}, p<0.05), \mathrm{MAGE}(2.7 \pm 0.4 \mathrm{vs} .1 .8 \pm 0.5 \mathrm{mmol} / \mathrm{L}$, $p<0.05$ ), and AUCpp ( $26.8 \pm 3.4 \mathrm{vs.} 19.2 \pm 3.2 \mathrm{mmol} / \mathrm{L} \cdot h, p<0.05)$, when compared to the control group, and the differences remained significant after adjusting for anthropometric indices and metabolic risk factors. Islet $\beta$ cell function index ISSI-2 in the pGDM group was lower than in the control group $(p<0.05)$. MBG, SDBG, MODD, MAGE and AUC $C_{p p}$ were all negatively associated with ISSI- 2 in the pGDM group $(r=-0.31,-0.30,-0.34,-0.48$ and -0.54 , respectively, $p<0.05)$, and the correlations remained significant after adjusting for anthropometric indices and metabolic risk factors.
\end{abstract}

Conclusions: Normal glucose tolerance women with pGDM were presented with elevated glycemic variability, which may be associated with impaired islet $\beta$ cell function.

Keywords: Glycemic variability, Normal glucose tolerance, Gestational diabetes mellitus

\section{Background}

Gestational diabetes mellitus (GDM) was associated with increased risks of developing postpartum pre-diabetes, type 2 diabetes and metabolic syndrome [1, 2]. The

\footnotetext{
*Correspondence: sujbzjx@163.com; wangxueqin@medmail.com.cn

${ }^{\dagger}$ Yong-mei Wang and Li-hua Zhao contributed equally to this work

2 Department of Endocrinology, The Second Affiliated Hospital

of Nantong University, No. 6 North Hai-er-xiang Road, Nantong 226001

China

Full list of author information is available at the end of the article
}

relationships reflected the fact that GDM and type 2 diabetes shared a similar pathophysiology, characterized by deficiency in islet $\beta$ cell secretion and insulin sensitivity $[3,4]$. GDM may serve as a window to reveal a predisposition to type 2 diabetes.

It also had been repeatedly demonstrated that women with previous GDM (pGDM) and even with postpartum normal glucose tolerance (NGT) carried deficiency in islet $\beta$ cell secretion and insulin sensitivity and subsequent altered glucose homeostasis [5-7]. Definition 
of NGT was based on fasting plasma glucose (FPG) $<5.6 \mathrm{mmol} / \mathrm{L}$ and 2-h postload plasma glucose (2hPG) $<7.8 \mathrm{mmol} / \mathrm{L}$ during a $75-\mathrm{g}$ oral glucose tolerance test (OGTT) [8]. Detection of glucose values at 0 and $120 \mathrm{~min}$ by OGTT may miss the potential glycemic variability. And previous studies conducted in NGT subjects at risks of developing diabetes showed that glycemic excursions were in the range of prediabetes as well as the diabetes $[9,10]$. So we hypothesized that women with pGDM and even with NGT status may have altered glycemic variability.

Efforts to quantify glycemic variability mainly relied on intermittent glucose determinations which acquired from the continuous glucose monitoring (CGM) system (CGMS), and CGM system can detect glycemic variability in more details than the conventional self-monitoring methods of blood glucose [11, 12]. Glycemic variability parameters estimated by the multiple modalities of CGM data [13] may differ in NGT women with and without the pGDM.

The present study was designed to investigate the glycemic variability assessed by CGM in postpartum NGT women with the pGDM.

\section{Methods}

\section{Study subjects}

This cross-sectional study was performed at outpatient and inpatient department of the Second Affiliated Hospital of Nantong University in China from January 2010 to May 2014. Total 502 women who had the diagnosis of GDM between 24 and 28th week of pregnancy were revisited and screened by 75 -g oral glucose tolerance test (OGTT) after delivery for 1 year. And 48 women, who detected with postpartum NGT and agreed to be performed with CGM, were recruited for the further study (pGDM group). The diagnoses of NGT and GDM were based on the criteria of the ADA 2008 [8]. NGT was defined as FPG $<5.6 \mathrm{mmol} / \mathrm{L}$ and $2 \mathrm{hPG}<7.8 \mathrm{mmol} / \mathrm{L}$ during the OGTT. GDM was made when two of the following plasma glucose values in the 75-g OGTT are exceeded: fasting, $5.3 \mathrm{mmol} / \mathrm{L} ; 1 \mathrm{~h}, 10.0 \mathrm{mmol} / \mathrm{L}$; $2 \mathrm{~h}, 8.6 \mathrm{mmol} / \mathrm{L}$. Meanwhile, 48 healthy women without pGDM, who selected and diagnosed with NGT after delivery for 1 year in the same department, were recruited and set as controls in the study (control group). The two groups were also matched for age and body mass index (BMI). And exclusion criteria for control group were as follows: family history of diabetes, lipid abnormalities, hypertension, hepatic disease, chronic kidney disease, cardiovascular disease, malignancy, or other disorders affecting glucose metabolism such as hyperthyroidism. The study was approved by the institutional review board of the Second Affiliated Hospital of
Nantong University, with written informed consent being obtained from all participants.

\section{$\beta$ cell function determination}

Blood samples were taken at 0, 30, 60, 120 and $180 \mathrm{~min}$ for the measurement of plasma glucose and insulin concentrations (glucose unit: $\mathrm{mmol} / \mathrm{L}$, insulin unit: $\mathrm{miu} / \mathrm{L}$ ) during 75-g oral glucose test. Glut and Inst represent the plasma glucose and insulin concentrations, respectively, at time $t$ during the OGTT. Insulin sensitivity was estimated using the insulin sensitivity index (ISI) of Matsuda and DeFronzo: ISI $=10,000 /$ square root of $(\mathrm{Ins} 0 \times \mathrm{Glu} 0) \times($ mean glucose $\times$ mean insulin during OGTT) [14]. Insulin secretion was defined as the ratio of the area-under-the-insulin-curve to the area-under-theglucose curve $\left(\mathrm{AUC}_{\mathrm{ins} / \mathrm{glu}}\right)[15,16]$. Integrated $\beta$ cell function was assessed with the Insulin Secretion-Sensitivity Index-2 (ISSI-2) $\left(\mathrm{AUC}_{\text {ins/glu }}\right.$ multiplied by ISI) $[16,17]$.

\section{CGM in all subjects}

After OGTT, all subjects were monitored by CGMS (Medtronic MiniMed, Northridge, CA 91325, USA) for $72 \mathrm{~h}$. The CGM system sensor was inserted in all subjects on day 0 and removed on day 3. Data were downloaded and glucose profiles were evaluated based on the data collected on days 1 and 2. The subjects were instructed to input at least four calibration readings per day and the times of key events. During the study, all subjects have standard meals provided by dietary division. The total calorie intake was $30 \mathrm{kcal} / \mathrm{kg}$ per day, with $50 \%$ carbohydrates, $15 \%$ proteins, and $35 \%$ fats. The calorie distribution between breakfast, lunch, and dinner was 20, 40, and $40 \%$, respectively. Three daily meals were required to consume at time of $6: 30-7: 30,11: 30-12: 30$, and 18:0019:00, respectively. All subjects were instructed to avoid strenuous exercise during CGM.

The parameters of glycemic variability included the standard deviation of blood glucose (SDBG), mean of daily continuous $24 \mathrm{~h}$ blood glucose (MBG), mean of daily differences (MODD), mean amplitude of glycemic excursions (MAGE) and the incremental areas above preprandial glucose values $\left(\mathrm{AUC}_{\mathrm{pp}}\right)$. MODD was calculated from the absolute difference between paired continuous glucose monitoring values during two successive $24 \mathrm{~h}$ periods and was used to assess inter-day glycemic variability [18]. MAGE, designed to quantify major swings of glycemia and to exclude minor ones, was used for assessing intra-day glycemic variability in this study [19]. $\mathrm{AUC}_{\mathrm{pp}}$, calculated incremental areas of glucose above the each meal, was performed to evaluate the characteristics of postprandial glucose excursion [20]. It should be noted that MBG was a measure of overall of glycemic level and not specifically variability [21]. 


\section{Anthropometric indices and laboratory examination}

Body mass index (BMI) was calculated $\left(\mathrm{kg} / \mathrm{m}^{2}\right)$. Systolic blood pressure (SBP) and diastolic blood pressure (DBP) taken three times using a sphygmomanometer and then averaged. Capillary glucose concentrations were measured with Lifescan Surestep blood glucose meter. Plasma glucose levels were measured using the glucose oxidase method. HbA1c was measured by high performance liquid chromatography (HPLC) with D-10 hemoglobin Testing Program (Bio-Rad). The serum insulin assay used magnetic beads-based enzymatic spectrofluorometric immunoassay with automatic enzyme immunoassay apparatus (AIA360, TOSOH). Serum glucose concentrations, total cholesterol (TC), triglyceride (TG), high density lipoprotein cholesterol (HDLC), and low density lipoprotein cholesterol (LDLC) were measured with Hitachi Model 7600 Series Automatic Analyzer.

\section{Statistical analyses}

Data analyses were performed using the SPSS16.0 statistical software (SPSS Inc., USA). Continuous variables were expressed as mean \pm standard deviation (SD) or median (interquartile range) in the case of skewed distributions. Categorical variables were described as frequency (percentage). The Student $t$ test was applied to compare differences of continuous variables between the pGDM and control groups, nonparametric test (MannWhitney U test) was applied to compare non-normally distributed variables between the two groups, and Chi squared test was applied to compare categorical variables between the two groups. Relationship between glycemic variability and integrated $\beta$ cell function was assessed using the Pearson's correlation test and partial correlation test. $p<0.05$ was considered to be statistically significant.

\section{Results}

Baseline characteristics in the subjects

As shown in Table 1, age, BMI and DBP were comparable between the pGDM and control groups $(p>0.05)$ SBP of pGDM group was higher than that in control group $(p<0.05)$. The prevalence of familial diabetes of pGDM group was higher than in control group $(p<0.05)$ TC, LDLC of pGDM group were higher than in control group $(p<0.05)$, HDLC of pGDM group was lower than in control group $(p<0.05)$, but there was no differences in TG between the two groups $(p>0.05)$. HbA1c of pGDM group was higher than that in control group $(p<0.05)$.

\section{Changes of plasma glucose and insulin concentrations during the OGTT, and $\beta$ cell functions derived from OGTT} The statistical comparisons of measurements characterizing the plasma glucose and insulin concentrations during the OGTT were summarized in Table 2. Plasma
Table 1 Comparisons of clinical variables in pGDM and control groups

\begin{tabular}{lllll}
\hline Variables & pGDM group & Control group & $\boldsymbol{t}$ & $\boldsymbol{p}$ \\
\hline$n$ & 48 & 48 & - & - \\
Age (year) & $29.1 \pm 4.1$ & $29.8 \pm 3.6$ & 0.941 & 0.349 \\
Familial diabetes, n (\%) & $7(14.6)$ & $0(0.0)$ & - & $0.012^{*}$ \\
BMI (kg/m $\left.{ }^{2}\right)$ & $26.8 \pm 3.2$ & $26.3 \pm 2.9$ & 0.768 & 0.444 \\
SBP $(\mathrm{mmHg})$ & $130 \pm 13$ & $119 \pm 15$ & 3.502 & 0.001 \\
DBP $(\mathrm{mmHg})$ & $76 \pm 9$ & $75 \pm 10$ & 0.493 & 0.623 \\
TG (mmol/L) & $1.5(1.2-2.0)$ & $1.3(1.2-1.8)$ & - & $0.442^{* *}$ \\
TC (mmol/L) & $6.2 \pm 1.0$ & $4.8 \pm 0.8$ & 8.320 & 0.000 \\
HDLC (mmol/L) & $1.1 \pm 0.3$ & $1.3 \pm 0.3$ & 2.265 & 0.026 \\
LDLC (mmol/L) & $3.3 \pm 0.9$ & $2.4 \pm 0.5$ & 6.588 & 0.000 \\
HbA1c (\%) & $5.8 \pm 0.4$ & $5.4 \pm 0.3$ & 8.617 & 0.000 \\
\hline
\end{tabular}

Normally distributed values in the table are given as the mean $\pm S D$, the nonnormally distributed values are given as the median ( 25 and $75 \%$ interquartiles) pGDM group: NGT women with the previous GDM; Control group: NGT women without the previous GDM

$B M I$ body mass index, SBP/DBP systolic/diastolic blood pressure, $T C$ total cholesterol; TG triglyceride, HDLC: high density lipoprotein cholesterol, LDLC low density lipoprotein cholesterol, HbA1c glycosylated hemoglobin A1c

* Test with Fisher's Exact test; ** Test with Mann-Whitney U test

glucose levels at baseline, 30, 60 and 120 min after glucose ingestion were higher in $\mathrm{pGDM}$ group was higher than that in control group $(p<0.05)$, plasma glucose level at $180 \mathrm{~min}$ had no significantly difference between the two groups $(p>0.05)$. Insulin concentration at $60 \mathrm{~min}$ was significantly higher in pGDM group than in control group $(p<0.05)$, but there were no differences in insulin concentrations at baseline, 30, 120 and 180 min between the two groups $(p>0.05)$. The area under the glucose curve $\left(\mathrm{AUC}_{\mathrm{glu}}\right)$ was significantly higher in $\mathrm{pGDM}$ group than in control group $(p<0.05)$, but the area under the insulin curve $\left(\mathrm{AUC}_{\mathrm{ins}}\right)$ was comparable between the pGDM and control groups $(p>0.05)$.

After comparison of insulin sensitivity and insulin secretion index derived from OGTT, insulin sensitivity index (Matsuda ISI) and insulin secretion index ( $\mathrm{AUC}_{\mathrm{ins} /}$ glu $)$ in pGDM group were lower than in control group $(p<0.05)$ (Table 2). Integrated $\beta$ cell function (ISSI-2) was significantly lower in pGDM group than in control group $(p<0.01)$.

\section{Glycemic variability in the subjects}

Glycemic variability detected from CGM system of pGDM and control groups were represented in Fig. 1. Although both pGDM and control groups were presented with NGT, the pGDM group had a greater MBG $(6.5 \pm 0.9$ vs. $5.9 \pm 0.8 \mathrm{mmol} / \mathrm{L}, p=0.004)$, SDBG $(1.3 \pm 0.3$ vs. $0.9 \pm 0.2 \mathrm{mmol} / \mathrm{L}, p=0.000), \mathrm{MODD}$ $(1.4 \pm 0.3$ vs. $1.1 \pm 0.2 \mathrm{mmol} / \mathrm{L}, p=0.002)$, MAGE 
Table 2 Comparisons of glucose and insulin concentrations during OGTT in PGDM and control groups

\begin{tabular}{lllll}
\hline Variables & pGDM group & Control group & $\boldsymbol{t}$ & $\boldsymbol{p}$ \\
\hline$n$ & 48 & 48 & - & - \\
Glu0 (mmol/L) & $5.5 \pm 0.6$ & $5.1 \pm 0.5$ & 3.845 & 0.000 \\
Glu30 (mmol/L) & $9.0 \pm 1.7$ & $7.5 \pm 1.4$ & 4.771 & 0.000 \\
Glu60 (mmol/L) & $8.8 \pm 2.8$ & $6.7 \pm 2.3$ & 4.071 & 0.000 \\
Glu120 (mmol/L) & $6.0 \pm 1.1$ & $5.4 \pm 1.4$ & 2.722 & 0.008 \\
Glu180 (mmol/L) & $4.9 \pm 1.0$ & $4.8 \pm 1.0$ & 0.677 & 0.500 \\
Ins0 (miu/L) & $6.3(3.9-9.7)$ & $5.6(4.0-7.8)$ & - & $0.391^{*}$ \\
Ins30 (miu/L) & $54.6(36.4-88.7)$ & $56.1(37.9-77.0)$ & - & $0.800^{*}$ \\
Ins60 (miu/L) & $63.1(40.9-85.0)$ & $44.1(28.5-65.4)$ & - & $0.011^{*}$ \\
Ins120 (miu/L) & $31.3(14.9-42.6)$ & $28.5(21.6-40.1)$ & - & $0.823^{*}$ \\
Ins180 (miu/L) & $9.2(5.5-13.6)$ & $8.1(4.7-17.2)$ & - & $0.496^{*}$ \\
AUC $_{\text {glu }}$ & $18.4 \pm 2.8$ & $15.7 \pm 2.5$ & 4.712 & 0.000 \\
(mmol/L·h) & & & & \\
AUC $_{\text {ins }}(\mathrm{miu} / \mathrm{L} \cdot h)$ & $114.7(74.17-$ & $99.6(75.2-132.1)$ & - & $0.356^{*}$ \\
AUC $_{\text {ins/glu }}$ & $163.8)$ & & & \\
ISI & $14.6(4.0-7.8)$ & $6.6(5.6-7.7)$ & - & $0.031^{*}$ \\
ISSI-2 $^{140.7(81.9-}$ & $155.0(120.3-$ & - & $0.034^{*}$ \\
& $190.0)$ & $205.7)$ & & \\
& $729.8(496.9-$ & $1027.2(872.7-$ & - & $0.000^{*}$ \\
& $943.0)$ & $1177.5)$ & &
\end{tabular}

Non-normally distributed values are given as the median ( 25 and $75 \%$ interquartiles)

pGDM group: NGT women with the previous GDM; Control group: NGT women without the previous GDM

Glut plasma glucose concentrations at time $t$ during OGTT, Inst plasma insulin concentrations at time $t$ during $\mathrm{OGTT}, A \cup C_{g / u}$ the area under the curve of glucose in $180 \mathrm{~min}, A U C_{\text {ins }}$ the area under the curve of insulin in $180 \mathrm{~min}, I S /$ insulin sensitivity index, $A U C_{\text {ins/g/u }}$ insulin secretion index, ISSI-2 insulin secretionsensitivity index-2

* Test with Mann-Whitney U test

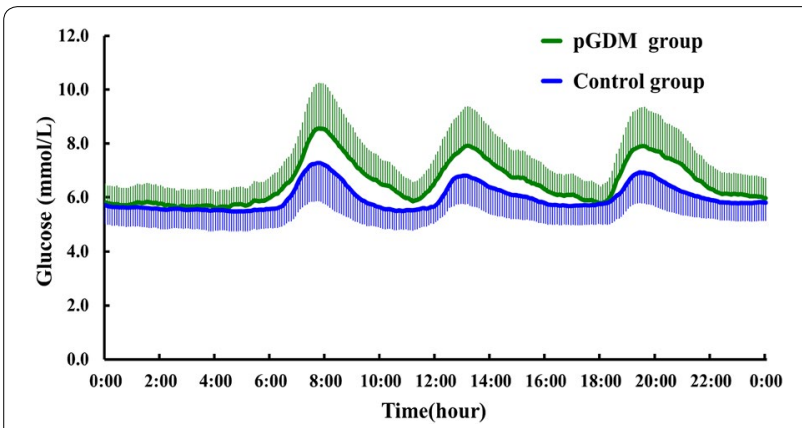

Fig. 1 Continuous glucose profiles represented mean data from $24 \mathrm{~h}$ in $\mathrm{PGDM}$ and control groups

(2.7 \pm 0.4 vs. $1.8 \pm 0.5 \mathrm{mmol} / \mathrm{L}, p=0.000)$, and $\mathrm{AUC}_{\mathrm{pp}}$ $(26.8 \pm 3.4$ vs. $19.2 \pm 3.2 \mathrm{mmol} / \mathrm{L} \cdot \mathrm{h}, p=0.000)$, when compared to the control group (Table 3). And the differences remained significant after adjusting for age, familial diabetes, BMI, SBP, DBP, TG, TC, HDLC and LDLC.
Table 3 Comparisons of glycemic variability parameters in $\mathrm{pGDM}$ and control groups

\begin{tabular}{|c|c|c|c|c|}
\hline Variables & pGDM group & Control group & $t$ & $p$ \\
\hline$n$ & 48 & 48 & - & - \\
\hline MBG (mmol/L) & $6.5 \pm 0.9$ & $5.9 \pm 0.8$ & 2.967 & 0.004 \\
\hline $\mathrm{SDBG}(\mathrm{mmol} / \mathrm{L})$ & $1.3 \pm 0.3$ & $0.9 \pm 0.2$ & 6.169 & 0.000 \\
\hline $\operatorname{MODD}(\mathrm{mmol} / \mathrm{L})$ & $1.4 \pm 0.3$ & $1.1 \pm 0.2$ & 3.186 & 0.002 \\
\hline MAGE (mmol/L) & $2.7 \pm 0.4$ & $1.8 \pm 0.5$ & 8.696 & 0.000 \\
\hline$A \cup C_{p p}(\mathrm{mmol} / \mathrm{L} \cdot \mathrm{h})$ & $26.8 \pm 3.4$ & $19.2 \pm 3.2$ & 11.267 & 0.000 \\
\hline
\end{tabular}

Normally distributed values in the table are given as the mean $\pm \mathrm{SD}$

pGDM group: NGT women with the previous GDM; Control group: NGT women without the previous GDM

$M B G$ mean of blood glucose, SDBG standard deviation of blood glucose, $M O D D$ mean of daily differences, MAGE mean amplitude of glycemic excursions, $A U C_{p p}$ incremental areas above preprandial glucose values

\section{Relationships between glycemic variability and ISSI-2 in pGDM group}

When the relationships between glycemic variability parameters and ISSI- 2 were analyzed by Pearson's correlation test, MBG $(r=-0.31, p=0.028)$, SDBG $(r=-0.30, p=0.037)$, MODD $(r=-0.34, p=0.017)$, MAGE $(r=-0.48, p=0.000)$ and $\mathrm{AUC}_{\mathrm{pp}}(r=-0.54$, $p=0.000)$ of pGDM group were all negatively associated with ISSI-2 in pGDM group (Fig. 2a-e). And the correlations remained significant after adjusting for age, familial diabetes, BMI, SBP, DBP, TG, TC, HDLC and LDLC.

\section{Discussion}

In the specific group of pGDM women, our present study found that these women even with postpartum NGT were presented with elevated glycemic variability parameters. CGM can provide additional glycemic information compared to OGTT. Detailed 24 h glycemic profiles can be documented by CGM. Certain groups at high risks of diabetes, with so-called NGT status based on the OGTT, were presented with elevated glycemic variability. The study by Ma et al. [22] demonstrated that glycemic variability was increased in abdominally obese men with NGT. A study conducted in cystic fibrosis patients, it had been observed that normoglycemic subjects by OGTT had glucose excursions in the prediabetes as well as the diabetes range [9]. Madhu et al. [10] showed the normoglycemic obese first-degree relatives of type 2 diabetes had excursions into the higher dysglycemic range when studied by CGMS, and $90 \%$ of subjects had excursions into the IGT range, and $15 \%$ had excursions into the diabetes range. A1c-Derived Average Glucose (ADAG) study [23] showed $93 \%$ of non-diabetic subjects exceeded the IGT threshold of $7.8 \mathrm{mmol} / \mathrm{L}, 7 \%$ of them reached diabetes threshold of $11.1 \mathrm{mmol} / \mathrm{L}$ during CGMS, and the mean $\mathrm{HbA1c}$ in these subjects was within the normal range 


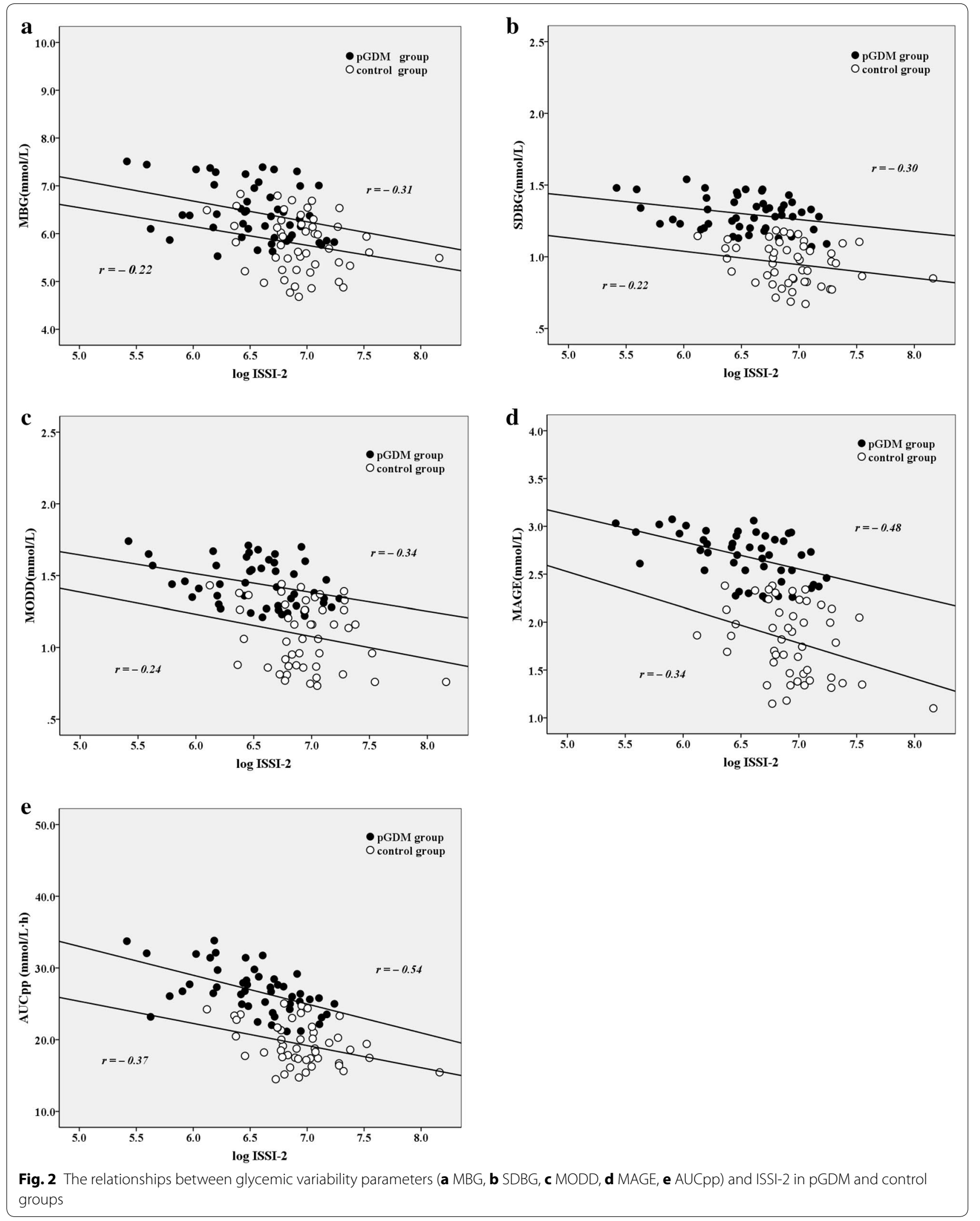


according to the ADA recommendations. Our previous study also showed that glycemic variability in normoglycemic subjects with elevated 1-h postload plasma glucose levels (NGT $1 \mathrm{~h} \geq 8.6 \mathrm{mmol} / \mathrm{L}$ group) was higher than those in NGT $1 \mathrm{~h}<8.6 \mathrm{mmol} / \mathrm{L}$ group [24]. Women with pGDM, and with postpartum NGT classified by the OGTT, had increased glycemic variability compared to NGT ones without pGDM in the present study. Glycemic variability parameters SDBG, MBG, MODD, MAGE and $\mathrm{AUC}_{\mathrm{pp}}$ were elevated in women with pGDM. Our finding demonstrated the characteristics of glycemic variability in NGT women with pGDM.

The pGDM identified a population of young women predisposed for type 2 diabetes and related cardiovascular disease. Retnakaran et al. $[25,26]$ showed any degree of abnormal glucose homeostasis detected on antepartum screening for GDM should be associated with an increased risk of postpartum pre-diabetes, diabetes and latent metabolic syndrome. Elevated circulating markers of endothelial dysfunction in young women with a history of GDM could reflect an early stage on the pathway to the manifestation of future cardiometabolic disorders [27]. And Bo et al. [28] showed women with previous GDM have been shown to express early markers of vascular dysfunction such as increased intima-media thickness of carotid arteries(C-IMT). Zajdenverg et al. [29] showed microcirculation abnormality, evaluated by papillae rectification, was carried in young non-diabetic women with pGDM. Our study showed the normoglycemic women with pGDM were presented with elevated glycemic variability parameters, when compared with the women without pGDM. And elevated glycemic variability could be considered as a marker of metabolic abnormality of pGDM.

Glycemic variability could be an independent risk factor for vascular complications in addition to average glucose [30,31]. Glucose variability parameters could be calculated with complex formulas designed specifically for the CGM data. In the previous studies, the SDBG around the mean glucose value was considered as a classical index to assess the glycemic variability [32]. MODD and MAGE are objective and valid indices to measure inter-day and intra-day glucose variability, respectively $[18,19]$. AUCpp was performed to evaluate the characteristics of postprandial glucose excursion [20]. And several studies had demonstrated that glycemic variability, assessed by MAGE, was closely associated with micro- and macro-vascular complications [33, 34]. Our presented study demonstrated that glycemic variability parameters SDBG, MBG, MODD, MAGE and $A U C_{p p}$ in pGDM group were higher than in the control group. Women with pGDM carried with early markers of vascular dysfunction [28, 29]. Hence, it implies that glycemic variability may be related to early markers of vascular dysfunction in women with pGDM. But it needs further study to document whether glycemic variability remission can improve the markers of vascular dysfunction in pGDM group.

GDM and type 2 diabetes shared a similar pathophysiology, characterized by deficiency in islet $\beta$ cell secretion and insulin sensitivity, and GDM was a stress situation that may reveal predisposition to type 2 diabetes. Previous studies had shown that women with previous GDM even with postpartum normal oral glucose tolerance test had both insulin secretion and action defects $[5,6]$. And our study showed insulin secretion and insulin sensitivity indices derived from OGTT were decreased in pGDM group than in control group. ISSI-2 proposed by Retnakaran et al. $[16,17]$ was a composite measure and may be a better index than either $\mathrm{AUC}_{\text {ins/glu }}$ or ISI alone to reflect the notion of declining $\beta$ cell function and account for glycemic disorders. After correlation analyzing, SDBG, MBG, MODD, MAGE, and $\mathrm{AUC}_{\mathrm{pp}}$ all negatively associated with the ISSI-2 in pGDM group. The decreased ISSI-2 of pGDM may be responsible for elevated glycemic variability.

It should be pointed out that our study had some limitations. First, the family history of diabetes could exaggerate the difference of glycemic variability between NGT women with and without previous GDM, but the comparison of glycemic variability between the two groups was adjusted for the familial diabetes. The pGDM group should be theoretically divided into subgroups with and without familial diabetes for further comparison, but the small sample size of subgroups might make some differences insignificant. Second, although we provided standard meals for subjects during the CGM system monitoring period, some factors, such as physical activity and emotional stress, etc., which may affect levels of glycemic variability, could not all be prevented. Third, we could not assess glycemic variability in relation to oxidative stress, inflammation and other markers of vascular dysfunction. The fourth limitation related to ISSI- 2 was that circulating insulin levels during the OGTT may be affected by other factors apart from $\beta$ cell function, such as incretin hormones and hepatic extraction. The two factors may limit the degree to which insulin levels during the OGTT can reflect $\beta$ cell function.

\section{Conclusions}

In summary, the glycemic variability parameters in NGT women with pGDM were higher than those in the NGT ones without pGDM, and elevated glycemic variability parameters may be associated with impaired $\beta$ cell function. 


\section{Abbreviations}

NGT: normal glucose tolerance; Pgdm: previous gestational diabetes mellitus; BMI: body mass index; SBP/DBP: systolic/diastolic blood pressure; TC: total cholesterol; TG: triglyceride; HDLC: high density lipoprotein cholesterol; LDLC: low density lipoprotein cholesterol; HbA1c: glycosylated hemoglobin a1 c; ISI: insulin sensitivity index; $\mathrm{AUC}_{\text {ins/glu: }}$ insulin secretion index; ISSI-2: insulin secretion-sensitivity index-2; SDBG: standard deviation of blood glucose; MODD: mean of daily differences; MAGE: mean amplitude of glycemic excursions; $\mathrm{AUC}_{\mathrm{pp}}$ : incremental areas above preprandial glucose values.

\section{Authors' contributions}

YW and LZ participated in the design of the study, data collection, analysis of the data, drafting of the manuscript. JS and XW (Xue-qin) conceived of the study, participated in its design and revised the manuscript. QH and TC participated in analysis of the data and revised the manuscript. XW (Xiao-hua), FX, JC and GW participated in data collection. All authors read and approved the final manuscript.

\section{Author details}

${ }^{1}$ Department of Gynaecology and obstetrics, The Second Affiliated Hospital of Nantong University, No. 6 North Hai-er-xiang Road, Nantong 226001, China. ${ }^{2}$ Department of Endocrinology, The Second Affiliated Hospital of Nantong University, No. 6 North Hai-er-xiang Road, Nantong 226001, China. ${ }^{3}$ Department of Clinical Laboratory, The Second Affiliated Hospital of Nantong University, No. 6 North Hai-er-xiang Road, Nantong 226001, China.

\section{Acknowledgements}

The study was funded by the Scientific Research Program of Nantong (No. HS2012028, HS2013006, HS149010).

\section{Compliance with ethical guidelines}

\section{Competing interests}

The authors declare that they have no competing interests.

Received: 17 June 2015 Accepted: 16 September 2015

Published online: 24 September 2015

\section{References}

1. Fernández-Morera JL, Rodríguez-Rodero S, Menéndez-Torre E, Fraga MF. The possible role of epigenetics in gestational diabetes: cause, consequence, or both. Obstet Gynecol Int. 2010;2010:605163.

2. Lauenborg J, Mathiesen E, Hansen T, Glümer C, Jørgensen T, Borch-Johnsen K, Hornnes P, Pedersen O, Damm P. The prevalence of the metabolic syndrome in a Danish population of women with previous gestational diabetes mellitus is three-fold higher than in the general population. J Clin Endocrinol Metab. 2005;90:4004-10.

3. Ben-Haroush A, Yogev Y, Hod M. Epidemiology of gestational diabetes mellitus and its association with Type 2 diabetes. Diabet Med. 2004;21:103-13.

4. Buchanan TA, Xiang AH. Gestational diabetes mellitus. J Clin Invest. 2005;115:485-91.

5. Kousta E, Lawrence NJ, Godsland IF, Penny A, Anyaoku V, Millauer BA, Cela E, Johnston DG, Robinson S, McCarthy MI. Insulin resistance and beta-cell dysfunction in normoglycaemic European women with a history of gestational diabetes. Clin Endocrinol (Oxf). 2003;59:289-97.

6. Ryan EA, Imes S, Liu D, McManus R, Finegood DT, Polonsky KS, Sturis J. Defects in insulin secretion and action in women with a history of gestational diabetes. Diabetes. 1995;44:506-12.

7. Seghieri G, Tesi F, Anichini R, De Bellis A, Barsotti E, Mari A, Ferrannini E. Influence of gestational diabetes on the long-term control of glucose tolerance. Diabetologia. 2007:50:2234-8.

8. American Diabetes Association. Diagnosis and classification of diabetes mellitus. Diabetes Care. 2008;31:S55-60.

9. Moreau F, Weiller MA, Rosner V, Weiss L, Hasselmann M, Pinget M, Kessler $\mathrm{R}$, Kessler L. Continuous glucose monitoring in cystic fibrosis patients according to the glucose tolerance. Horm Metab Res. 2008;40:502-6.
10. Madhu SV, Muduli SK, Avasthi R. Abnormal glycemic profiles by CGMS in obese first-degree relatives of type 2 diabetes mellitus patients. Diabetes Technol Ther. 2013;15:461-5.

11. Klonoff DC, Buckingham B, Christiansen JS, Montori VM, Tamborlane WV Vigersky RA, Wolpert H, Endocrine Society. Continuous glucose monitoring: an Endocrine Society Clinical Practice Guideline. J Clin Endocrinol Metab. 2011;96:2968-79.

12. Chinese Diabetes Society. Chinese clinical guideline for continuous glucose monitoring (2012). Chin Med J (Engl). 2012;125:4167-74.

13. Hill NR, Oliver NS, Choudhary P, Levy JC, Hindmarsh P, Matthews DR. Normal reference range for mean tissue glucose and glycemic variability derived from continuous glucose monitoring for subjects without diabetes in different ethnic groups. Diabetes Technol Ther. 2011;13:921-8.

14. Matsuda M, DeFronzo RA. Insulin sensitivity indices obtained from oral glucose tolerance testing: comparison with the euglycemic insulin clamp. Diabetes Care. 1999;22:1462-70.

15. Retnakaran R, Hanley AJ, Raif N, Hirning CR, Connelly PW, Sermer M, Kahn $\mathrm{SE}$, Zinman B. Adiponectin and beta cell dysfunction in gestational diabetes: pathophysiological implications. Diabetologia. 2005;48:993-1001.

16. Retnakaran R, Shen S, Hanley AJ, Vuksan V, Hamilton JK, Zinman B. Hyperbolic relationship between insulin secretion and sensitivity on oral glucose tolerance test. Obesity (Silver Spring). 2008;16:1901-7.

17. Retnakaran R, Qi Y, Goran MI, Hamilton JK. Evaluation of proposed oral disposition index measures in relation to the actual disposition index. Diabet Med. 2009;26:1198-203.

18. Zhou J, Li H, Ran X, Yang W, Li Q, Peng Y, Li Y, Gao X, Luan X, Wang W, Jia $W$. Establishment of normal reference ranges for glycemic variability in Chinese subjects using continuous glucose monitoring. Med Sci Monit. 2011;17:CR9-13.

19. Service FJ. Glucose variability. Diabetes. 2013;62:1398-404.

20. Zhou J, Jia W, Bao Y, Ma X, Lu W, Li H, Hu C, Xiang K. Glycemic variability and its responses to intensive insulin treatment in newly diagnosed type 2 diabetes. Med Sci Monit. 2008;14:CR552-8.

21. Chen T, Xu F, Su JB, Wang XQ, Chen JF, Wu G, Jin Y, Wang XH. Glycemic variability in relation to oral disposition index in the subjects with different stages of glucose tolerance. Diabetol Metab Syndr. 2013;5:38.

22. Ma CM, Yin FZ, Wang R, Qin CM, Liu B, Lou DH, Lu Q. Glycemic variability in abdominally obese men with normal glucose tolerance as assessed by continuous glucose monitoring system. Obesity (Silver Spring). 2011;19:1616-22

23. Borg R, Kuenen JC, Carstensen B, Zheng H, Nathan DM, Heine RJ, Nerup J, Borch-Johnsen K, Witte DR, ADAG Study Group. Real-life glycaemic profiles in non-diabetic individuals with low fasting glucose and normal HbA1c: the A1C-Derived Average Glucose (ADAG) study. Diabetologia. 2010;53:1608-11.

24. Su JB, Chen T, Xu F, Wang XQ, Chen JF, Wu G, Jin Y, Wang XH. Glycemic variability in normal glucose regulation subjects with elevated 1 -h postload plasma glucose levels. Endocrine. 2014;46:241-8.

25. Retnakaran R, Qi Y, Connelly PW, Sermer M, Zinman B, Hanley AJ. Glucose intolerance in pregnancy and postpartum risk of metabolic syndrome in young women. J Clin Endocrinol Metab. 2010;95:670-7.

26. Retnakaran R, Qi Y, Sermer M, Connelly PW, Hanley AJ, Zinman B. Glucose intolerance in pregnancy and future risk of pre-diabetes or diabetes. Diabetes Care. 2008;31:2026-31.

27. Bo S, Valpreda S, Menato G, Bardelli C, Botto C, Gambino R, Rabbia C Durazzo M, Cassader M, Massobrio M, Pagano G. Should we consider gestational diabetes a vascular risk factor? Atherosclerosis. 2007;194:e72-9.

28. Zajdenverg L, Rodacki M, Faria JP, Pires ML, Oliveira JE, Halfoun VL. Precocious markers of cardiovascular risk and vascular damage in apparently healthy women with previous gestational diabetes. Diabetol Metab Syndr. 2014;6:63.

29. Göbl CS, Bozkurt L, Yarragudi R, Prikoszovich T, Tura A, Pacini G, Koppensteiner R, Kautzky-Willer A. Biomarkers of endothelial dysfunction in relation to impaired carbohydrate metabolism following pregnancy with gestational diabetes mellitus. Cardiovasc Diabetol. 2014;13:138.

30. Zaccardi F, Pitocco D, Ghirlanda G. Glycemic risk factors of diabetic vascular complications: the role of glycemic variability. Diabetes Metab Res Rev. 2009;25:199-207.

31. Brownlee M, Hirsch IB. Glycemic variability: a hemoglobin A1 C-independent risk factor for diabetic complications. JAMA. 2006;295:1707-8. 
32. Rodbard D. New and improved methods to characterize glycemic variability using continuous glucose monitoring. Diabetes Techno Ther. 2009;11:551-65.

33. Xu F, Zhao LH, Su JB, Chen T, Wang XQ, Chen JF, Wu G, Jin Y, Wang XH. The relationship between glycemic variability and diabetic peripheral neuropathy in type 2 diabetes with well-controlled $\mathrm{HbA}$ 1c. Diabetol Metab Syndr. 2014;6:139.
34. Su G, Mi SH, Tao H, Li Z, Yang HX, Zheng H, Zhou Y, Tian L. Impact of admission glycemic variability, glucose, and glycosylated hemoglobin on major adverse cardiac events after acute myocardial infarction. Diabetes Care. 2013:36:1026-32.

Submit your next manuscript to BioMed Central and take full advantage of:

- Convenient online submission

- Thorough peer review

- No space constraints or color figure charges

- Immediate publication on acceptance

- Inclusion in PubMed, CAS, Scopus and Google Scholar

- Research which is freely available for redistribution

Submit your manuscript at

www.biomedcentral.com/submit

C Biomed Central 